\title{
RETO ECONÓMICO, VALORES Y RELIGIÓN EN LAS ELECCIONES NACIONALES DE COSTA RiCA 2018
}

Economic Challenges, Values and Religion in the

Costa Rican 2018 Elections

\section{ADRIÁN PIGNATARO}

Universidad de Costa Rica

\section{ILKA TREMINIO}

Universidad de Costa Rica

\section{RESUMEN}

Por la radicalización de la oferta partidaria, la pérdida de protagonismo de los partidos tradicionales y la inesperada continuidad en el poder del partido oficialista con la presidencia de Carlos Alvarado, Costa Rica vivió, en 2018, elecciones inéditas. Durante la campaña, el foco de atención giró de temas económicos hacia temas de autoexpresión (educación sexual, matrimonio igualitario, aborto). En conjunto con variables sociodemográficas y la valoración del gobierno saliente, la religión tuvo un peso explicativo importante en la orientación del voto, especialmente tras la opinión consultiva de la Corte IDH que reconoció derechos fundamentales a la población LGBTI durante la campaña. Se discuten las consecuencias para el presente gobierno y las futuras elecciones.

Palabras clave: elecciones, economía, valores, comportamiento político, Costa Rica

\begin{abstract}
In 2018 Costa Rica faced unprecedented elections due to the radicalization of the party supply, the diminished role of the traditional parties, and the unexpected continuity in government of the incumbent party with the presidency of Carlos Alvarado. During the campaign, the focus shifted from economic to self-expression issues (sexual education, equal marriage, abortion). Together with sociodemographic variables and the evaluation of the incumbent government, religion had an important explanatory weight on vote choice, especially after the advisory opinion of the Inter-American Court that recognized the fundamental rights of LGBTI people during the campaign. We discuss the consequences for the current government and the future elections.
\end{abstract}

Key words: elections, economy, values, political behavior, Costa Rica 


\section{INTRODUCCIÓN}

Las elecciones nacionales de 2018 — presidenciales y legislativas-representaron un evento de particular relevancia para la democracia costarricense. Por un lado, se mantuvieron las tendencias del reciente período multipartidista, tales como la fragmentación partidaria, la volatilidad y la postergación de la decisión del voto (Sánchez 2003; Vargas-Cullell 2007; Alfaro-Redondo y GómezCampos 2014; Pignataro 2017b;); por el otro, los comicios de 2018 destacaron por el surgimiento de figuras populistas de derecha radical, como el candidato Juan Diego Castro del Partido Integración Nacional y Fabricio Alvarado del partido, de corte neopentecostal, Restauración Nacional. Este último candidato logró pasar, con el mayor número de votos, a la segunda vuelta electoral, enfrentándose al candidato oficialista, Carlos Alvarado, quien finalmente ganó la elección presidencial revirtiendo los resultados de la primera vuelta. Aunque el desenlace dio continuidad al partido en el gobierno, el auge que el discurso religioso tomó en la recta final de las elecciones modificó el comportamiento electoral y rearticuló el panorama político costarricense. Además, el nuevo gobierno se vio obligado a establecer acuerdos legislativos más allá de su partido, formando oficialmente el primer gobierno de coalición con este objetivo.

Este artículo examina las elecciones de 2018 — su contexto, campaña y resultados- profundizando en tres temas claves para comprender la coyuntura: valores y religiosidad entre el electorado, radicalización de la oferta partidaria y determinantes individuales del voto. En las conclusiones se discuten las implicaciones de esta elección para el primer año del nuevo gobierno y para el futuro de la democracia costarricense.

\section{CONTEXTO PREVIO A LA ELECCIÓN}

Entre 1953 y 1998 la política costarricense se caracterizó por la estabilidad democrática del régimen y la alternancia entre dos fuerzas políticas: el Partido Liberación Nacional (PLN) y el Partido Unidad Social Cristiana (PUSC), incluyendo los predecesores históricos de este último. Desde 2002, sin embargo, el sistema bipartidista se fragmentó como consecuencia de una convergencia ideológica entre ambas corrientes partidarias y de un ambiente de apatía política y denuncias de corrupción (Raventós et al. 2005; Booth 2007). El sistema electoral proporcional para el nivel legislativo, existente desde 1949, favoreció el paulatino posicionamiento de partidos emergentes con representación parlamentaria. Sin embargo, no fue hasta 2014 que uno de estos nuevos actores, el Partido Acción Ciudadana (PAC), alcanzó el puesto más alto del Poder Ejecutivo a través de Luis Guillermo Solís.

La presidencia de Solís enfrentó el doble reto de asumir el primer gobierno del PAC y de carecer de mayoría parlamentaria (Treminio 2016). Siguiendo un ciclo clásico de popularidad de "luna de miel" desgaste y recuperación (Carlin et al. 
2018), Solís inició el mandato con una aprobación de casi 40 \% (valoraciones "muy buena" y buena") que, un año después, descendió hasta menos del 20 \% (gráfico 1). Entre marzo y julio de 2017 la imagen del gobierno se recuperó tras su positivo desempeño al enfrentar el huracán Otto y de la inauguración de un puente con impacto nacional. Empero, hacia el final del mandato se desató un escándalo en torno a un empresario y su negocio de importación de cemento chino que involucró préstamos bancarios irregulares y un supuesto tráfico de influencias en los trámites de aprobación en distintas entidades públicas, lo cual implicó a altos cargos de gobierno y del Poder Judicial. Este caso, denominado por la prensa como el "cementazo", supuso cuestionamientos para el presidente Solís que perjudicaron la reputación del PAC, partido que nació haciendo del discurso anticorrupción el centro de su propuesta.

Gráfico 1. Aprobación del gobierno saliente

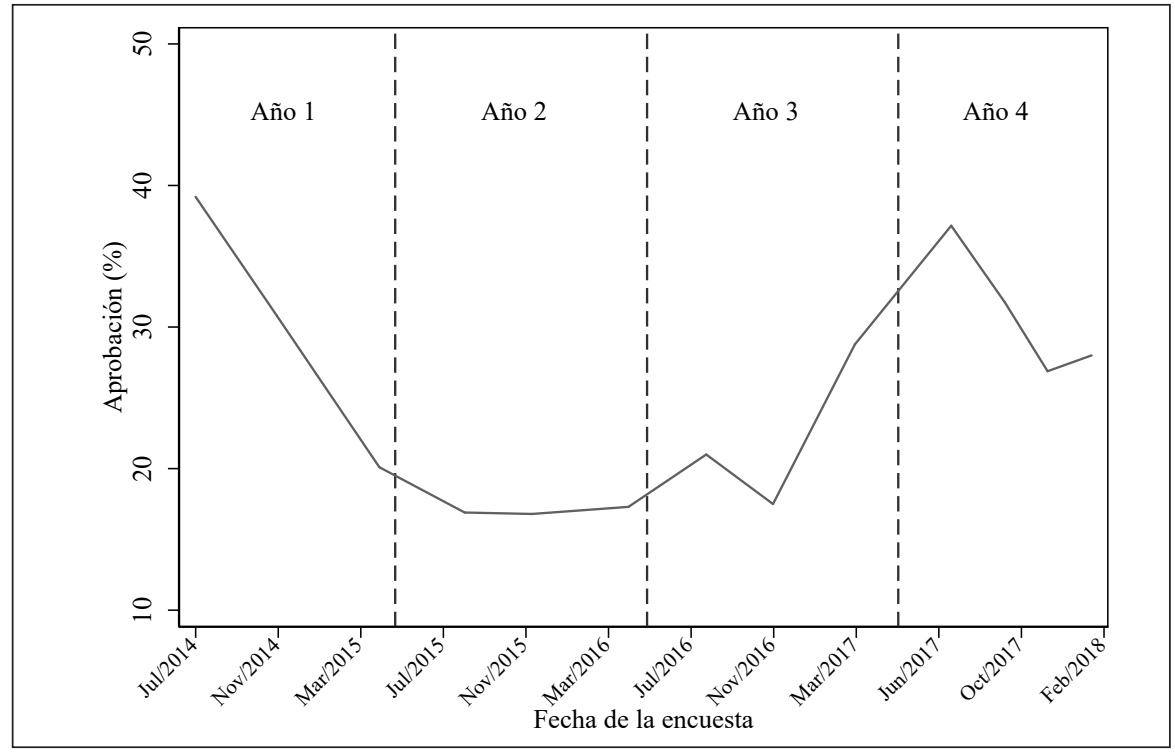

Fuente: elaboración propia con base en CIEP (2014-2018)

En el último año del gobierno de Solís, la economía resaltó como tema prioritario. Iniciándose la campaña electoral en octubre de 2017, el desempleo y la situación económica punteaban como los principales problemas del país entre el público (CIEP 2017). Esta percepción negativa sobre la economía tenía correlato con los datos reales de acuerdo con varios indicadores. El producto interno bruto (PIB) per cápita creció a un ritmo menor en 2017 que en 2016 (2,0\% vs. 2,9 \%). La inflación de 2,6 \%, sin llegar a niveles alarmantes, representó un alza respecto a los dos años anteriores de gobierno (Programa Estado de la Nación 2018: 93-99). Adicionalmente, el equilibrio fiscal se agravó en tanto el gasto público aumentó en las últimas tres administraciones, mientras que las reformas orientadas a 
incrementar los ingresos estatales, hasta ese momento, fracasaron (Borges 2017). El déficit fiscal creció desde 2009 hasta llegar a 6,2 \% en 2017 (Programa Estado de la Nación 2018), por lo cual los gobiernos hicieron frente a las necesidades de financiamiento estatal con la emisión de deuda, que a finales del período de Solís llegó a representar 40 \% del pIB. Este escenario económico llevó al presidente a advertir problemas de liquidez para enfrentar los gastos públicos, incluyendo salarios y subsidios. El resultado fue un deterioro en la imagen de competencia del gobierno en materia económica y no una salida a la crisis, pese a que en la Asamblea Legislativa se encontraba una serie de proyectos de ley que pretendían atender la situación fiscal.

Los retos económicos, no obstante, sobrepasan una única presidencia. Costa Rica, si bien es catalogado como país de renta media y alto desarrollo humano, ha convivido con un $20 \%$ de pobreza desde 1994 que no ha logrado reducir sustancialmente, aunque de 2016 a 2017 la pobreza extrema disminuyó de 6,3 a 5,7 \% (Programa Estado de la Nación 2018: 56). Por otro lado, la desigualdad, medida a través del coeficiente de Gini, ha aumentado de forma sostenida en las últimas décadas. El desempleo abierto también ha repuntado en los últimos años, llegando casi a $9 \%$ (gráfico 2$)^{1}$.

Gráfico 2. Evolución histórica del coeficiente de Gini y la tasa de desempleo

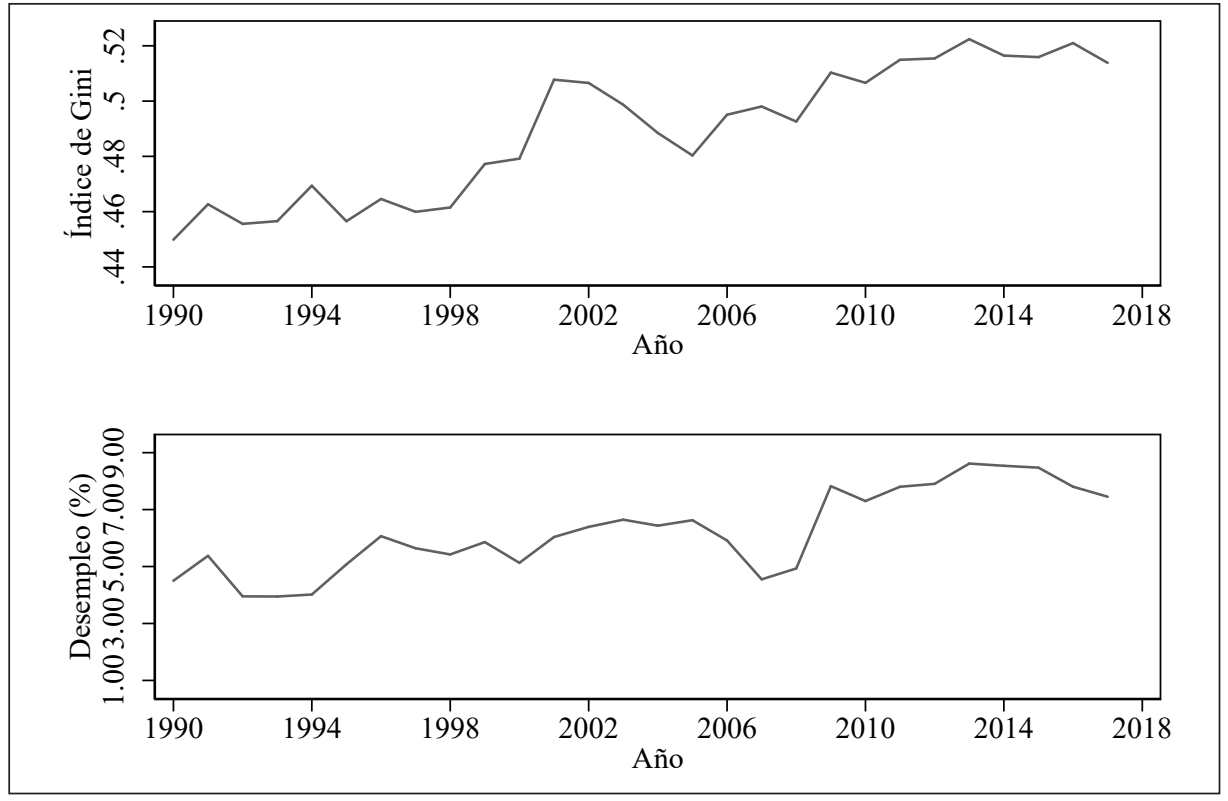

Fuente: elaboración propia con datos compilados por el Programa Estado de la Nación (2017)

Datos obtenidos de la Encuesta Nacional de Hogares. La Encuesta Continua de Empleo registra porcentajes mayores cercanos al $10 \%$. 
El estancamiento de la pobreza, el aumento de la desigualdad y el alza en el desempleo, particularmente en el segmento juvenil, apuntan a una situación de privación económica con posibles repercusiones políticas. La mayoría de los partidos, así como la opinión pública, coinciden en que la pobreza, el desempleo y el déficit fiscal son problemas prioritarios que deben ser resueltos (Programa Estado de la Nación 2018: 218-219). Por lo tanto, se preveía que la ciudadanía iba a votar según la competencia partidaria (Green y Jennings 2017), evaluando cuál partido se considera más capacitado para solucionar los problemas económicos.

Por otro lado, la privación económica y la desigualdad son detonantes de conflictos culturales. Inglehart (2018) teoriza que la ansiedad económica se traduce en inseguridad existencial, mayor religiosidad y menor tolerancia hacia decisiones individuales como el aborto, el divorcio y la homosexualidad. En resumen, el contexto económico influye tanto en el corto plazo, en términos de la competencia partidaria para atender los problemas que afligen al país, como en el largo, en la adquisición de valores y normas de autoexpresión. En las siguientes secciones veremos cómo se manifestaron ambos factores durante la campaña política.

\section{CAMPAÑNA POLÍTICA Y ELECCIONES}

Podemos dividir la campaña electoral en tres fases: la primera se desarrolló en un contexto de incertidumbre dados los altos porcentajes de electores indecisos; en la segunda parte el ambiente se polarizó, como resultado de un fallo de la Corte Interamericana de Derechos Humanos sobre matrimonio igualitario; mientras la tercera, de cara al balotaje, implicó un reacomodo de fuerzas políticas y una división cultural y religiosa.

Para las elecciones presidenciales de 2018 se inscribieron trece partidos políticos: doce candidatos y una sola candidata, cada uno acompañado de dos vicepresidentes en una misma papeleta. De manera concurrente con las presidenciales se realizaron elecciones legislativas, para renovar la totalidad de la Asamblea Legislativa.

Al inicio de la campaña (primera fase), las encuestas preelectorales mostraban que 40,0 \% del electorado no había decidido su voto, porcentaje que se mantuvo prácticamente invariable hasta las semanas cercanas a la elección (tabla 1). Este fenómeno ha sido constante en las recientes elecciones (Pignataro 2017b). La postergación del voto y la menor identificación partidaria generan una dinámica electoral más volátil y resultados menos predecibles. En consecuencia, entre octubre y diciembre de 2017 no había un ganador predefinido.

En las encuestas de 2017 las intenciones de voto estuvieron encabezadas por los partidos tradicionales (PLN y PUSC), que mantienen un núcleo (reducido) de partidarios fieles, así como por la debutante candidatura de Juan Diego Castro desde el Partido Integración Nacional (PIN), la cual resultó llamativa 
por las características disruptivas de su discurso. Castro, un mediático abogado penalista, se imponía mediante un discurso populista y antielitista. No es de extrañar, por lo tanto, que sus críticas se dirigieran principalmente contra los candidatos de los partidos tradicionales: el candidato del PLN, Antonio Álvarez, es un político con amplia experiencia legislativa y en el Ejecutivo (además de empresario); Rodolfo Piza, candidato del PUSC, fungió como presidente ejecutivo de la Caja Costarricense del Seguro Social, juez suplente y candidato presidencial en 2014; Carlos Alvarado, joven candidato del gobierno saliente del PAc en el cual se desempeñó como ministro, mantenía bajo apoyo electoral al cerrar el año. En ese momento, el salmista y diputado Fabricio Alvarado del partido minoritario Restauración Nacional (RN), cuyo apoyo creció en el primer mes de 2018, no figuraba como un candidato con posibilidades de alcanzar la presidencia según encuestas preelectorales.

Tabla 1. Intención de voto (en porcentajes)

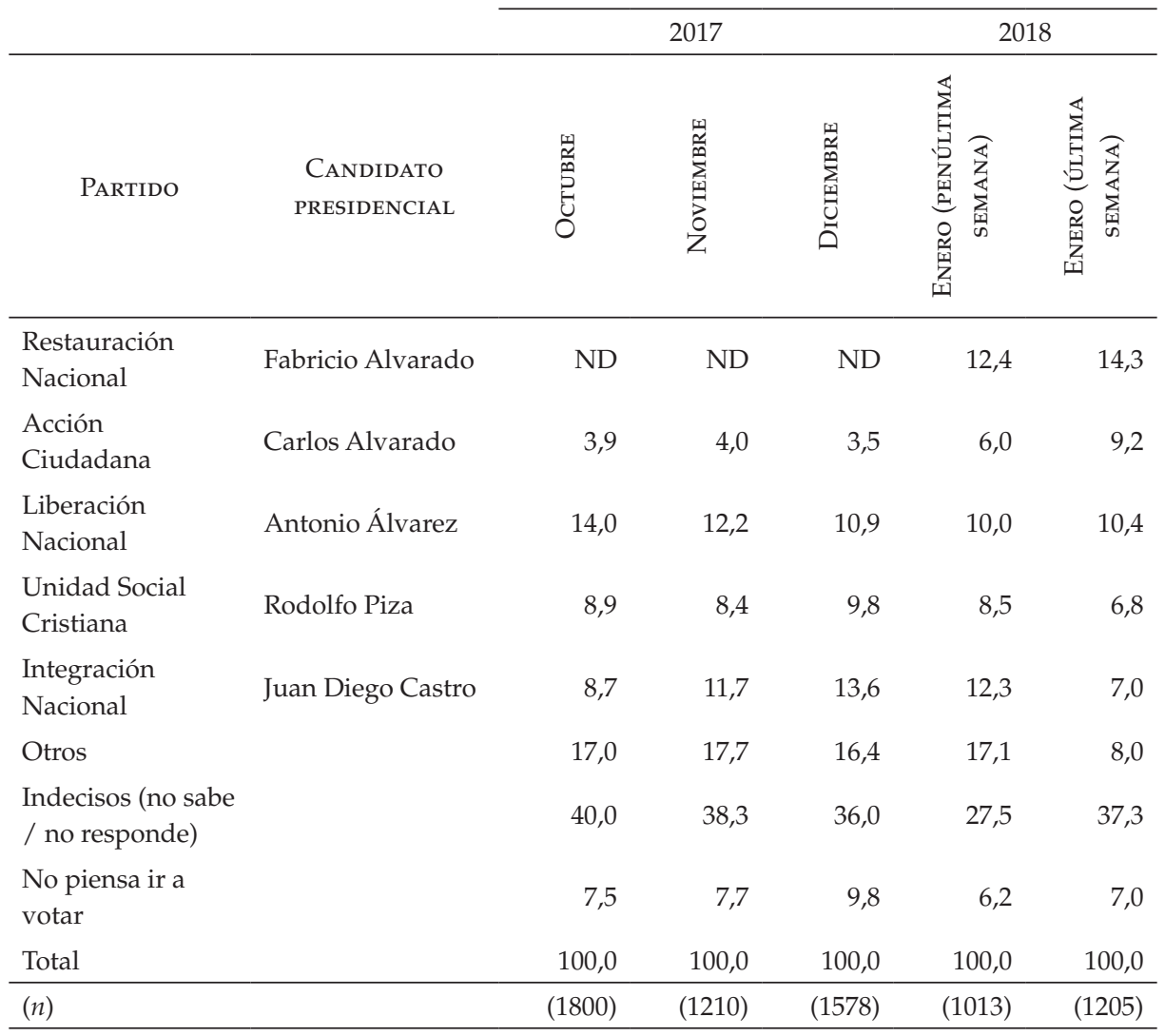

ND: dato no disponible

Fuente: elaboración propia con base en CIEP (2014-2018) 
Un punto de inflexión ocurrió el 9 de enero de 2018, a un mes de las elecciones, cuando se publicó el fallo de la Corte Interamericana de Derechos Humanos (Corte IDH) sobre la opinión consultiva OC-24/17, solicitada por la entonces vicepresidenta de Costa Rica Ana Helena Chacón. Esta resolución indica que "es necesario que los Estados garanticen [...] el derecho al matrimonio, para asegurar la protección de todos los derechos de las familias conformadas por parejas del mismo sexo" (Corte Interamericana de Derechos Humanos 2017: 88). Reafirma, además, el cambio de nombre como un derecho conforme a la identidad de género autopercibida.

Con este acontecimiento se abre una segunda etapa en la campaña electoral, marcada por una fuerte división en la opinión pública: del $75 \%$ que se enteró de la resolución, 58 \% se opuso, 29 \% estuvo de acuerdo y 12 \% no emitió opinión (CIEP 2018). Los candidatos a la presidencia también tomaron posición, algunos de ellos respetuosos de la jurisdicción de la Corte IDH, aunque la mayoría sin apoyar el matrimonio igualitario. Por el contrario, Fabricio Alvarado, de RN, manifestó que de ser electo presidente desconocería el fallo y sacaría a Costa Rica de la Corte. Esto lo convirtió en el más beligerante opositor de la opinión consultiva, que lo catapultó en las encuestas hasta posicionarlo en primer lugar en intención de voto.

En esta segunda fase la discusión pública se centró en temas culturales, no solo el matrimonio igualitario sino el aborto (en Costa Rica la ley lo permite únicamente cuando la vida de la madre está en peligro, aunque no se ha aprobado la norma técnica necesaria para su aplicación), la educación en salud sexual y reproductiva en escuelas y colegios públicos y la confesionalidad del Estado (la Constitución establece que la religión católica romana es la oficial). Las políticas progresistas y seculares fueron reducidas a la noción de "ideología de género" por sus opositores (Arguedas-Ramírez 2018). Con la mayoría de la opinión pública costarricense favoreciendo las posiciones conservadoras (ver sección IV), el candidato Fabricio Alvarado declaraba hablar en nombre de la mayoría religiosa y cristiana del país. Merece la pena agregar en este aspecto que los partidos que representan ideologías neopentecostales han enfatizado en otros países, como Brasil, la oposición al matrimonio de personas del mismo sexo (Kourliandsky 2019: 143). Esta temática, por tanto, no era ajena a la agenda de Fabricio Alvarado, quien en sus discursos de campaña invitó a los votantes a concebir las elecciones como un referéndum sobre el matrimonio entre hombre y mujer.

Entre los pocos candidatos que apoyaba la resolución de la Corte IDH se encontraba el oficialista Carlos Alvarado, de manera coherente con la iniciativa de consulta impulsada por su partido, junto a partidos minoritarios de izquierda. En síntesis, una semana antes de la elección los partidos se dividían entre aquellos opuestos al matrimonio igualitario — RN, PLN, PUSC y PIN- y el PAC a favor, con más de una tercera parte del electorado indecisa. 


\section{Resultados de la primera vuelta}

Un total de 3.322.239 electores se registraron para votar en una de las 6.612 juntas receptoras de votos (Tribunal Supremo de Elecciones 2018). Al igual que en 2014, se habilitó el voto en el extranjero para la elección presidencial. En la primera vuelta, efectuada el 4 de febrero, se contabilizó una participación electoral de $65,7 \%^{2}$. Este porcentaje de afluencia resulta menor que en la anterior elección nacional (68,2 \%) e inferior a la media de 1998-2014 (68,3\%), período en el que se registró un declive de participación respecto a 1962-1994 (promedio de 81,1 $\%$ ). Incluso en una era de menor participación, la abstención en 2018 fue alta.

Estudios previos han analizado en profundidad los factores sociodemográficos, psicológicos y contextuales que influencian la participación electoral (Hernández 1991; Raventós et al. 2005, 2012; Ramírez 2010; Remmer 2010; Alfaro-Redondo 2014; Pignataro y Cascante 2018). Uno de ellos es el ciclo de vida: como en otros países, la participación es baja entre personas jóvenes, aumenta con la edad y decae en los últimos años de vida (gráfico 3). No obstante, en Costa Rica las personas con 18 años votan excepcionalmente más de lo que se esperaría para su edad, interpretado como "el entusiasmo de votar por primera vez" (Hernández 1991: 132). Es también recurrente que las mujeres voten más que los hombres hasta alrededor de los 70 años, cuando la relación se invierte y son los segundos quienes asisten mayoritariamente a las urnas.

Gráfico 3. Participación electoral según edad y sexo (primera vuelta)

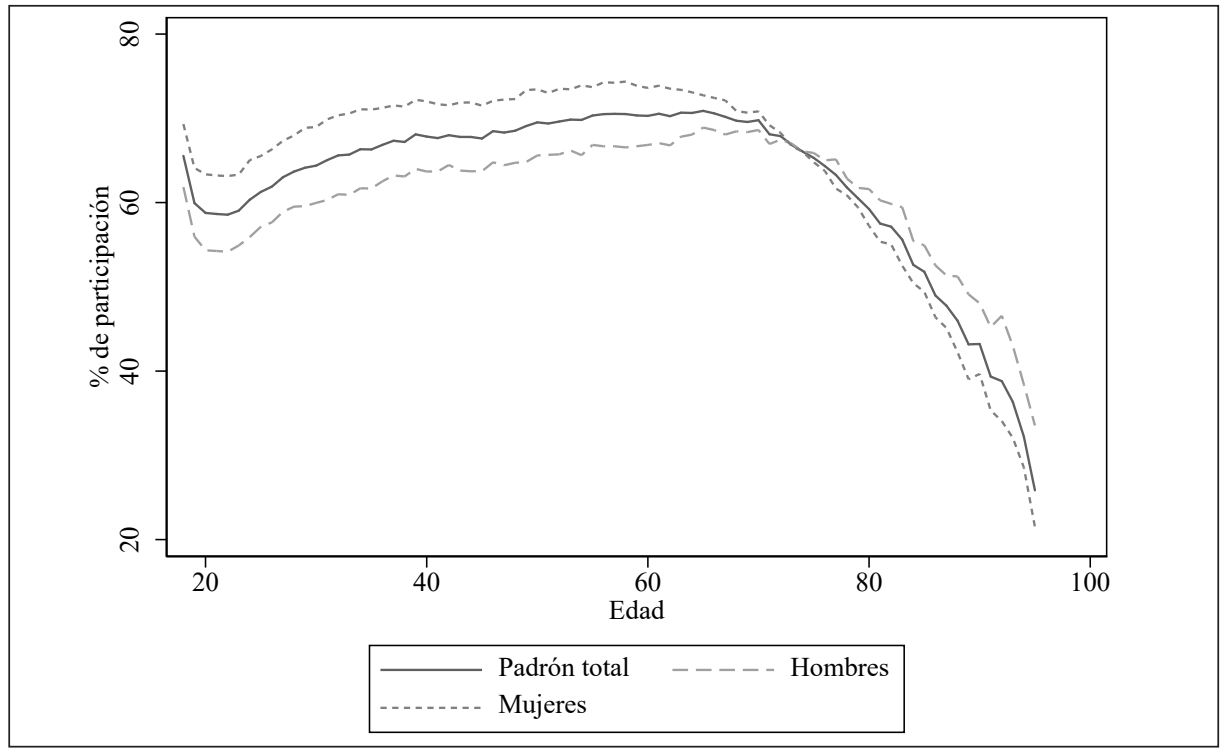

Fuente: elaboración propia con base en datos del Tribunal Supremo de Elecciones 
$\mathrm{Al}$ igual que las encuestas preelectorales no lograron vislumbrar con certeza los resultados, la primera ronda tampoco definió el ganador. Restauración Nacional obtuvo la mayor pluralidad de votos con un $25 \%$, pero no alcanzó el umbral del $40 \%$ de los votos válidos, por lo que se efectuó una segunda vuelta entre los dos partidos más votados; el segundo lugar lo obtuvo Acción Ciudadana, cuyo apoyo electoral ascendió notablemente hasta 21,6 \%. Ambas fuerzas se enfrentarían, el 6 de abril, en el balotaje.

Tabla 2. Resultados oficiales de la primera vuelta

\begin{tabular}{|c|c|c|c|c|}
\hline Partido & $\begin{array}{c}\text { CANDIDATO } \\
\text { PRESIDENCIAL }\end{array}$ & $\begin{array}{l}\text { PORCENTAJE DE } \\
\text { VOTOS VÁLIDOS } \\
\text { (PRESIDENCIAL) }\end{array}$ & $\begin{array}{l}\text { PoRCENTAJE DE } \\
\text { VOTOS VÁLIDOS } \\
\text { (LEGISLATIVAS) }\end{array}$ & $\begin{array}{l}\text { NÚMERO dE } \\
\text { ESCAÑ̃S }\end{array}$ \\
\hline $\begin{array}{l}\text { Restauración } \\
\text { Nacional }\end{array}$ & Fabricio Alvarado & 25,0 & 18,2 & 14 \\
\hline $\begin{array}{l}\text { Acción } \\
\text { Ciudadana }\end{array}$ & Carlos Alvarado & 21,6 & 16,3 & 10 \\
\hline $\begin{array}{l}\text { Liberación } \\
\text { Nacional }\end{array}$ & Antonio Álvarez & 18,6 & 19,5 & 17 \\
\hline $\begin{array}{l}\text { Unidad Social } \\
\text { Cristiana }\end{array}$ & Rodolfo Piza & 16,0 & 14,6 & 9 \\
\hline $\begin{array}{l}\text { Integración } \\
\text { Nacional }\end{array}$ & Juan Diego Castro & 9,5 & 7,7 & 4 \\
\hline $\begin{array}{l}\text { Republicano } \\
\text { Social Cristiano }\end{array}$ & Rodolfo Hernández & 4,9 & 4,2 & 2 \\
\hline $\begin{array}{l}\text { Movimiento } \\
\text { Libertario }\end{array}$ & Otto Guevara & 1,0 & 2,3 & 0 \\
\hline Frente Amplio & Edgardo Araya & 0,8 & 4,0 & 1 \\
\hline $\begin{array}{l}\text { Nueva } \\
\text { Generación }\end{array}$ & Sergio Mena & 0,8 & 2,1 & 0 \\
\hline $\begin{array}{l}\text { Alianza } \\
\text { Demócrata } \\
\text { Cristiana }\end{array}$ & Mario Redondo & 0,6 & 2,4 & 0 \\
\hline $\begin{array}{l}\text { Renovación } \\
\text { Costarricense }\end{array}$ & Stephanie Campos & 0,6 & 2,0 & 0 \\
\hline $\begin{array}{l}\text { Accesibilidad sin } \\
\text { Exclusión }\end{array}$ & Óscar López & 0,3 & 2,2 & 0 \\
\hline $\begin{array}{l}\text { De los } \\
\text { Trabajadores }\end{array}$ & Jhonn Vega & 0,2 & 0,5 & 0 \\
\hline Otros & & & 4,1 & 0 \\
\hline Total & & 100,0 & 100,0 & 57 \\
\hline
\end{tabular}

Fuente: Tribunal Supremo de Elecciones 
Aunque es la tercera elección en que la presidencia se decide en segundo turno, varios hechos resultaron sorpresivos en 2018: es la primera ocasión en que ninguno de los dos viejos actores de la era bipartidista — PLN y PUSC - participa en el balotaje, RN amplió el apoyo electroral recibido (en 2014 obtuvo 1,3 \% de los votos), y tampoco se esperaba que el PAc alcanzara los votos necesarios para pasar a la segunda ronda dada la impopularidad del gobierno saliente (del cual su candidato presidencial fue ministro) y la baja intención de voto que reflejaron las encuestas.

Los resultados legislativos mantienen una relativa correspondencia con los presidenciales. Siete partidos obtuvieron escaños en alguna de las siete circunscripciones electorales (con magnitud promedio de 8,1). Aunque llegan dos partidos menos en la legislatura 2014-2018, las fracciones resultan más numerosas, de modo que el número efectivo de partidos legislativos varió ligeramente (de 4,9 a 4,7 en 2018), mostrando una asentada fragmentación partidaria. Lo que resulta aún más significativo es que ningún partido obtuvo mayoría en el parlamento.

En términos de distribución geográfica, entre las tres fuerzas con mayor número de diputados, RN y PLN obtuvieron legisladores en las siete provincias (que corresponden a las circunscripciones electorales), mientras el PAC solo alcanzó representación en cuatro (aquellas de mayor magnitud de distrito que componen el Gran Área Metropolitana y que muestran los niveles más altos de participación electoral), sin obtener ningún diputado en provincias costeras.

En cuanto a la representación de mujeres, los comicios legislativos debían cumplir con la regla de paridad de género vertical puesta en práctica desde la anterior elección de 2014; sin embargo, el vacío respecto a la alternancia entre listas paridad horizontal - impidió que en aquella elección los partidos realizaran los encabezamientos de sus listas con mujeres, lo que repercutió en una caída del número de diputadas con respecto al período en el que se aplicaba la cuota de 40 \% de mujeres. En 2018, con la aplicación de la alternancia vertical y horizontal, los resultados llevaron a un total de 26 mujeres al Congreso (45\%), cifra que si bien no alcanza aún el $50 \%$ muestra incremento y permite la Asamblea con más mujeres en la historia costarricense. No obstante, prospectivamente la mayor presencia de legisladores de partidos conservadores en el Congreso podría provocar un efecto neutralizador en el avance de los derechos de las mujeres, que estos consideran parte de la "ideología de género"3. 


\section{Movilización de actores políticos hacia la segunda vuelta y resultados}

De cara a la segunda vuelta electoral, la cual designamos como tercera etapa, la tensión política provocada por la polarización de las opciones electorales creó un ambiente de búsqueda de adhesiones tanto a RN como al PAC. Se trataba de un período de medición de fuerzas en las que los perdedores de la primera vuelta tomaron partido de acuerdo con sus agendas y con sus pronósticos electorales.

Fabricio Alvarado había ganado la primera ronda con un mayor número de votos y, por tanto, era esperable una repetición de ese triunfo. A diferencia del balotaje de 2014 en el que un candidato desistió de competir (ver Treminio 2016), esta vez la campaña adquirió un gran dinamismo. Ambos partidos capturaron personalidades destacadas de la política (exministros, líderes de opinión), con algunas distinciones. Por un lado, RN tuvo un fuerte apoyo del sector empresarial y de políticos con orientación conservadora y tradicional; por el otro, el PAC aglutinó a sectores socialdemócratas y progresistas, además de recibir la notoria adhesión del candidato del Pusc, Rodolfo Piza.

Como se observa en la tabla 3, la encuesta de febrero de 2018 del cIEP mostraba una intención de voto muy reñida entre los candidatos. Esta corta distancia pudo haber animado el surgimiento de un grupo compuesto fundamentalmente por personas jóvenes denominado "Coalición por Costa Rica", el cual buscaba frenar el triunfo electoral de Restauración Nacional. El colectivo agrupó numerosos y diversos miembros del territorio nacional y de diferentes partidos políticos a través de círculos de coordinación y evitando la construcción de liderazgos visibles y nodales dentro de la red. Tuvo una presencia importante en redes sociales, pero también en las comunidades en las que trabajaron para frenar el avance de RN.

En el mismo mes se registró otro efecto de corto plazo de campaña, cuando los medios viralizaron mensajes emitidos por el pastor neopentecostal Ronny Chaves, líder religioso de Fabricio Alvarado y empresario del canal internacional Enlace TV. Entre estos se encontraba uno en el que el líder asimilaba a la Virgen de los Ángeles, uno de los símbolos más importantes del catolicismo costarricense, a un "demonio". En el video se le oía expresar que: "La Virgen de los Ángeles es un espíritu babilónico que debe caer, si queremos un avivamiento en Costa Rica [...]" (Ruiz 2018, 18 de marzo). Con este enunciado, el pastor de la teología de la prosperidad causó disgusto en la población católica del país. El reportaje hacía referencia también a la opulencia y excentricidad del pastor, características de los líderes neopentecostales, generando controversia en la opinión pública ${ }^{4}$. Aunque es difícil estimar el peso que esta publicación

4 En este fragmento que la prensa reprodujo del pastor Chaves se encuentran elementos discursivos del pentecostalismo de la tercera ola, o neopentecostalismo, que recoge los fundamentos de la "teología de la prosperidad" y la "teología de la guerra espiritual". La primera defiende la idea de que "Dios creó a sus hijos para ser prósperos y obtener la felicidad integral en este mundo"; la segunda manifiesta que "el mundo es un campo de batalla entre las fuerzas del bien y las del mal". Ambas teologías se complementan pues consideran que las fuerzas del mal (que corresponden a cualquier distracción del camino único) se apoderan 
específica tuvo en el electorado, algunos datos que se exploran más adelante (sección VI) muestran que profesar la religión católica o protestante constituyó uno de los predictores relevantes del voto.

El acervo católico en Costa Rica es sólido, en comparación con el resto de Centroamérica (aunque muestra una tendencia a la disminución, en relación inversa con la expansión de iglesias evangélicas). Costa Rica se ubica entre los países de América Latina mayoritariamente católicos, con $62 \%$ de personas afiliadas al catolicismo, frente a $25 \%$ que se identifica como protestantes y $9 \%$ que no profesa religión (Pew Research Center 2014, 13 de noviembre).

En este escenario se puede argumentar que el triunfo electoral en primera ronda requería de una proporción de votos mucho menor que la necesaria para aglutinar una mayoría contundente en el balotaje. En la primera ronda, para el partido RN podía ser suficiente el electorado proveniente del segmento evangélico. No así en la segunda, en la que necesitaba sobrepasar los votos del PAC, sobre todo ante una polarización que provocó tanto el avivamiento en la defensa de los católicos de sus símbolos como el resguardo del valor secular de la política entre los no practicantes. Así, aunque RN creció en número de votos en la segunda vuelta, quedó por debajo de los votantes del PAC, que expandió y diversificó su apoyo.

La última encuesta que publicó el ciep en marzo acercaba aún más a los dos candidatos, pero persistía un $18 \%$ de personas indecisas (tabla 3 ). Con estos pronósticos en ciernes, la campaña experimentó en los últimos días una inusitada movilización que se tradujo en el aumento de la participación electoral con respecto a la primera vuelta: $66,4 \%$ de electores asistieron a ejercer el voto, en una jornada que quedó atrapada entre los días de asueto nacional que se dan durante la Semana Santa y que incluso atrajo a costarricenses que no se habían inscrito a tiempo para votar en el exterior.

Al cierre de las urnas había gran incertidumbre; no obstante, el Tribunal Supremo de Elecciones dio los resultados con el 91 \% de las mesas escrutadas a tan solo dos horas de haber concluido las votaciones. El resultado final declaró presidente a Carlos Alvarado, del PAC, con 60,6 \%. La rapidez y contundencia de la declaratoria generó cuestionamientos de parte de los restauracionistas, quienes alegaron fraude electoral; sin embargo, estas acusaciones fueron disipándose en el curso de la oficialización de la declaratoria y de la recepción en físico del material electoral.

de los fieles, quienes deben ser exorcizados por sus líderes religiosos para liberarlos de demonios que les impiden alcanzar la prosperidad (Oro y Tadvald 2019: 57). La defensa de un camino único hacia la verdad hace que el neopentecostalismo no acepte un diálogo interreligioso, sino que polariza entre el bien y el mal (Kourliandsky 2019: 142). 
Tabla 3. Intención de voto y resultados oficiales de la segunda vuelta (en porcentajes)

\begin{tabular}{|c|c|c|c|c|}
\hline \multirow[b]{3}{*}{ PARTIDO } & \multirow[b]{3}{*}{$\begin{array}{c}\text { CANDIDATO } \\
\text { PRESIDENCIAL }\end{array}$} & \multirow{2}{*}{\multicolumn{2}{|c|}{ INTENCIÓN DE VOTO }} & \multirow{3}{*}{$\begin{array}{c}\text { Resultados } \\
\text { Votos válidos }\end{array}$} \\
\hline & & & & \\
\hline & & FEBRERo & Marzo & \\
\hline Acción Ciudadana & Carlos Alvarado & 40,4 & 44,4 & 60,6 (ganador) \\
\hline $\begin{array}{l}\text { Restauración } \\
\text { Nacional }\end{array}$ & Fabricio Alvarado & 32,7 & 36,8 & 39,4 \\
\hline $\begin{array}{l}\text { Indecisos (no sabe / } \\
\text { no responde) }\end{array}$ & & 25,6 & 18,2 & \\
\hline No piensa ir a votar & & 1,3 & 0,7 & \\
\hline Total & & 100,0 & 100,0 & 100,0 \\
\hline (n) & & (920) & (1041) & \\
\hline
\end{tabular}

Fuente: CIEP (2014-2018); Tribunal Supremo de Elecciones

\section{VALORES DE AUTOEXPRESIÓN Y SECULARIDAD}

Al iniciarse la campaña electoral para la primera vuelta los asuntos que principalmente preocupaban a la población eran económicos: desempleo, inflación y déficit fiscal. Estos se definen como temas de valencia (valence issues) en contraste con los temas de posición (position issues) (Stokes 1963). Los primeros son aquellos que la mayoría quisiera ver resueltos, de modo que los partidos se diferencian en términos de la competencia que proyectan para atender los problemas; los segundos implican preferencias diversas (y opuestas) sobre la acción que el gobierno debe tomar, por ello, los partidos se diferencian por la posición que toman al respecto.

Con el fallo de la Corte IDH sobre matrimonio igualitario, los temas de valencia pasaron a un segundo plano y la agenda estuvo dominada por temas sobre asuntos culturales y de autoexpresión. La prensa tituló el fenómeno como un "shock religioso" y el mismo candidato Fabricio Alvarado anunció "que el 4 de febrero [la primera vuelta] sea nuestro referendo sobre matrimonio hombre y mujer" (Chinchilla 2018, 10 de enero), relegando la discusión sobre la economía y otros temas salientes.

Se ha señalado ya que la mayoría de la opinión pública se opuso a la resolución. En primera instancia, debe tenerse presente que la mayor parte de las personas costarricenses son religiosas, en términos de identidad y de práctica. Ya que altos niveles de religiosidad se asocian con actitudes conservadoras sobre secularidad y valores de autoexpresión (Inglehart 2018), resulta comprensible que, en Costa Rica, 57 \% apruebe la confesionalidad constitucional del Estado, $66 \%$ se oponga al matrimonio civil entre personas del mismo sexo y $64 \%$ no acepte al aborto incluso en caso de violencia sexual (CIEP 2018). 
Además, estas preferencias sobre secularidad y autoexpresión están fuertemente correlacionadas con la intención de voto. Al construir una escala de conservadurismo basada en los tres ítems de confesionalidad, matrimonio igualitario y aborto (donde el valor máximo de tres indica el total de preferencias conservadoras), se observan variaciones significativas entre los votantes por partido (gráfico 4) ${ }^{5}$. Los electores de Restauración Nacional (RN) presentan la media superior en la escala de conservadurismo $(2,3)$; es decir, este grupo de votantes se opone a dos normas de autoexpresión en promedio. Por el contrario, los electores de Acción Ciudadana (PAC) constituyen el grupo menos conservador $(0,7)$. Los votantes de Liberación Nacional (PLN) y de Integración Nacional (PIN) tienden más hacia el conservadurismo, mientras que los de Unidad Social Cristiana (PUSC) se acercan más al promedio de los votantes del PAC. Este último resultado es importante ya que fueron estos dos partidos los que formaron la alianza más significativa de cara a la segunda vuelta y la subsiguiente coalición de gobierno. Quienes en el momento de la encuesta no pensaban votar o se mantenían indecisos indican valores promedio de conservadurismo, lo cual evidencia que su conformación era bastante heterogénea.

Gráfico 4. Conservadurismo según intención de voto (15-17 de enero de 2018)

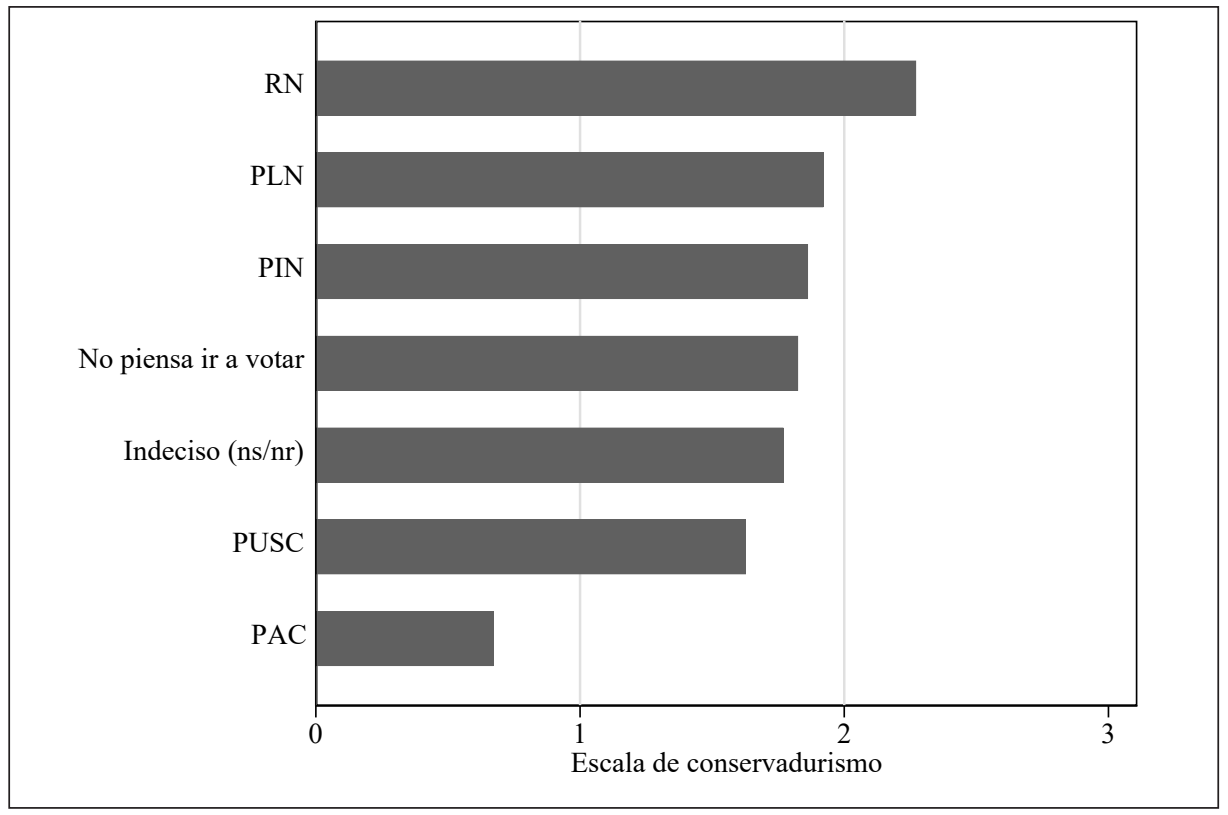

Fuente: elaboración propia con base en CIEP (2014-2018)

Se excluyen otros partidos ya que las muestras resultaban demasiado pequeñas para generar inferencias robustas. 


\section{RADICALIZACIÓN DE LA OFERTA PARTIDARIA}

Los principales participantes del proceso electoral se pueden clasificar en dos tipos. PLN, PUSC y PAC, aunque programáticamente variados, se definen como partidos mainstream en tanto han liderado en oportunidades anteriores el gobierno y sus ideologías no son extremas. Por el contrario, RN y PIN muestran características particularmente distintivas. El primero se ha asumido como un partido de corte neopentecostal, cuyos cuadros provienen mayoritariamente de iglesias evangélicas; el segundo se define en términos personalistas en referencia a su candidato presidencial Juan Diego Castro, quien originalmente no militaba en el PIN, sino que fue adoptado para lanzar su candidatura. Sostenemos que ambos partidos se asemejan entre sí y se distinguen de los demás por haber articulado discursos de derecha radical populista en las elecciones de $2018^{6}$.

Según Mudde (2010: 1173-1175), el núcleo ideológico de la derecha radical populista es la combinación de nativismo, autoritarismo y populismo. El nativismo se refiere a la idea de una nación homogénea amenazada por elementos (personas e ideas) no nativas; el autoritarismo es la preferencia por una sociedad estrictamente ordenada, donde las faltas a la autoridad son castigadas de manera severa; el populismo, por su parte, se asume como una ideología débil que separa el "pueblo puro" de la elite corrupta y sostiene que la política es la expresión de la voluntad general del pueblo.

Estos tres elementos encuentran referentes empíricos en RN y PIN y en sus respectivos candidatos presidenciales, que identificamos con base en reportajes de prensa y en los programas partidarios. En primer lugar, el nativismo se manifestó a través de posturas xenófobas: el PIN se definió como una agrupación "enemiga de la migración" (Arrieta 2017, 8 de junio), mientras que RN prometió en su plan de gobierno una política migratoria más estricta e indicó que convertiría la migración en un "tema país" (Cascante 2018, 27 de marzo; Restauración Nacional 2018: 81). El nativismo se expresó también en una vertiente soberanista, opuesta a organismos internacionales, en especial contra la Corte IDH, la cual, según Fabricio Alvarado, "está violentando la soberanía de este país" (Valverde 2018, 23 de enero) ${ }^{7}$. Un nativismo de índole cultural se observó también cuando Alvarado refirió a Costa Rica como un pueblo homogéneo, demarcado por la religión, un país donde "imperan valores judeocristianos" (Chinchilla 2018, 10 de enero).

El autoritarismo destacó en las propuestas de Castro en materia de seguridad, que se resumen con la etiqueta de "mano dura": penas más severas, énfasis en labores policiales, oposición a beneficios carcelarios para la ejecución de

$6 \quad$ Para Kourliandsky (2019: 146), el andamiaje del pentecostalismo se estructura en un pensamiento de derecha radical. Kernecker y Wagner (2019) catalogan a RN como un niche party, por su reducida agenda temática y características organizativas. Ambas clasificaciones, sin embargo, no son excluyentes, ya que examinan diferentes dimensiones.

7 Un antecedente importante es la condena que recibió Costa Rica en 2012 de la Corte IDH por no permitir la fecundación in vitro. El gobierno Solís se vio forzado a regular el procedimiento vía decreto en 2015. 
la pena (Alfaro 2018, 31 de enero). También Fabricio Alvarado, en el trayecto hacia la segunda vuelta y contando con el apoyo del asesor de seguridad del ya derrotado Castro, prometió "mano dura" en seguridad (Cascante 2018, 27 de marzo).

El populismo fue asociado con Juan Diego Castro de forma recurrente. La crítica a los partidos que han gobernado fue central en su campaña, marcando una división entre el pueblo y los políticos; por ejemplo, en su plan de gobierno anuncia que pretende empoderar "a los ciudadanos en la lucha contra la corrupción" (Partido Integración Nacional 2017: 32). Debido a sus estridentes y ofensivos ataques a la elite política, a funcionarios estatales y a los medios de comunicación, el candidato Castro suscitó comparaciones con el presidente de Estados Unidos Donald Trump (Sequeira 2017, 30 de mayo; Murillo 2017, 6 de diciembre). En la propuesta de RN también se revela el discurso populista. En el plan de gobierno se identificaba a los políticos "adalides de la ideología de género, hoy día incrustados en las principales cimas del poder" (elite corrupta) que atacan "todas las formas de religión, pero sobre todo a las iglesias cristianas evangélicas y católicas, que representan las creencias del $90 \%$ de los costarricenses" (pueblo puro), discriminando y promoviendo ideas "abiertamente nazi fascistas" ( $\underline{\text { sic }}$; Restauración Nacional 2017: 49). Resumimos el análisis de las tres dimensiones en la tabla 4.

Tabla 4. Elementos discursivos de derecha radical populista

\begin{tabular}{|c|c|c|}
\hline PARTIDO & INTEGRACIÓN NACIONAL & RESTAURACIÓN NACIONAL \\
\hline $\begin{array}{l}\text { Nativismo / } \\
\text { soberanismo }\end{array}$ & Antiinmigración & $\begin{array}{l}\text { Corte IDH atenta contra la } \\
\text { soberanía } \\
\text { Pueblo culturalmente homogéneo } \\
\text { Antiinmigración }\end{array}$ \\
\hline Autoritarismo & $\begin{array}{l}\text { Política de seguridad de "mano } \\
\text { dura" }\end{array}$ & $\begin{array}{l}\text { Política de seguridad de "mano } \\
\text { dura" }\end{array}$ \\
\hline Populismo & $\begin{array}{l}\text { Partidos tradicionales son } \\
\text { corruptos }\end{array}$ & $\begin{array}{l}\text { Políticos en el poder atacan la } \\
\text { religión del pueblo }\end{array}$ \\
\hline
\end{tabular}

Fuente: elaboración propia

La radicalización de la oferta partidaria en la democracia costarricense no debe ser subestimada. Aunque su protagonismo resulta novedoso, no se trata de una anomalía ya que otras democracias consolidadas han visto crecer y llegar al poder partidos populistas radicales. La creciente desconfianza política presente en Costa Rica desde fines de los años noventa-, la ansiedad económica y la revancha cultural antes las políticas progresistas constituyen algunas de las explicaciones más asentadas sobre la emergencia de este tipo de partidos (ver Golder 2016). Futuras investigaciones deberían ahondar las causas en el caso costarricense. 


\section{DETERMINANTES DEL VOTO}

Para explicar el comportamiento individual del voto en las dos vueltas electorales se consideran cuatro grupos de variables explicativas, teniendo en cuenta la lectura contextual anterior, las previsiones teóricas y la disponibilidad de los datos: (1) variables sociodemográficas: edad, sexo y nivel educativo; (2) religión: identidad religiosa y práctica medida como la frecuencia con que asiste a actividades religiosas; (3) economía personal: tenencia de casa propia, ingreso subjetivo y si es habitante de provincia central o periférica ${ }^{8}$ y (4) temas de valencia: principales problemas del país y las evaluaciones retrospectivas del gobierno y de la economía. Otras variables explicativas, como la percepción del candidato y la imagen de competencia de los partidos, no estaban disponibles.

Para el análisis de la primera vuelta se estimó un modelo de regresión logístico multinomial donde la variable dependiente es el voto por Restauración Nacional (RN), Acción Ciudadana (PAC) y otros partidos. Los datos provienen de una encuesta poselectoral realizada en marzo por el Centro de Investigación y Estudios Políticos (CIEP) .

Los resultados de la estimación se resumen en el gráfico 5, que representa los efectos marginales estimados en cambios en la probabilidad del voto, manteniendo constantes las demás variables. Todas las variables - continuas y categóricas- se codifican entre 0 y 1 , de modo que los efectos son fácilmente comparables.

8 En promedio, las provincias periféricas (Guanacaste, Puntarenas y Limón) concentran mayor pobreza, desempleo y desigualdad que las provincias centrales (San José, Alajuela, Heredia y Cartago). Los análisis ecológicos observaron variaciones en la distribución del voto (Programa Estado de la Nación 2018).

9 La encuesta poselectoral es de modalidad telefónica. El trabajo de campo se realizó entre el 19 y el 21 de marzo, completando 1.202 entrevistas. Como se sabe, por factores cognitivos y técnicos los porcentajes de voto de una encuesta no son idénticos a los datos oficiales. Mientras que los votos válidos son 25,0 \% para RN y $21,6 \%$ para PAC, la encuesta registra respectivamente $28,8 \%$ y $28,1 \%$ (con margen de error de \pm 3.0 puntos porcentuales para ambos porcentajes). 
Gráfico 5. Efectos marginales en la estimación del voto para la primera vuelta (modelo multinomial)

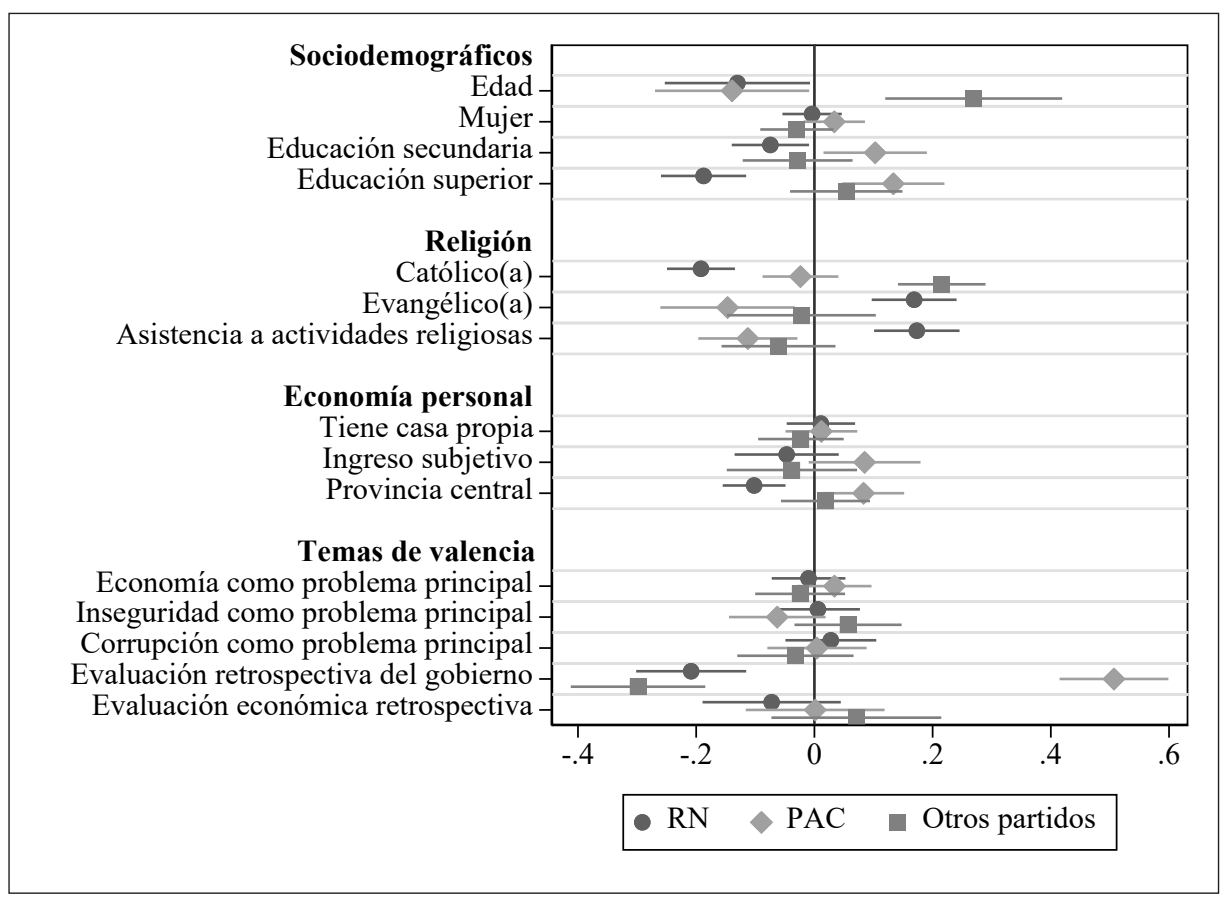

Fuente: Análisis de regresión con base en la encuesta poselectoral de marzo de 2018 del cIEP

En el análisis se obtiene que una menor edad aumentó la probabilidad de votar tanto por RN como por PAC, en contraste con electores mayores, quienes, con mayor probabilidad, votaron por otros partidos. Los niveles educativos secundario y superior incrementaron la probabilidad del voto por el PAC, mientras que disminuyeron la probabilidad de voto por RN (el efecto es nulo para los otros partidos). No se observan diferencias significativas según sexo.

Las variables religiosas tuvieron un peso considerable en esta elección. Identificarse como católico produjo un cambio en la probabilidad de votar por otros partidos de 0,20 puntos porcentuales, mientras que el voto por RN disminuye casi en la misma magnitud. A su vez, el ser evangélico aumentó la propensión a votar por RN, mientras que disminuyó por PAC (siendo indiferente para otros partidos). Una mayor frecuencia de asistencia a actividades religiosas, que se vincula con actitudes menos seculares y contrarias a valores de autoexpresión, se correlaciona con el voto por $\mathrm{RN}$, mientras que reprime el voto por PAC.

La economía personal impactó en menor magnitud y los intervalos de error indican efectos no significativos, excepto en el caso de provincia: habitar en un 
territorio central aumentó la probabilidad del voto por el PAC, mientras que en provincias periféricas el voto tendió hacia RN.

En cuanto a los temas de valencia, aunque la identificación de un problema principal (economía, inseguridad y corrupción) no se relacionó con el voto, la evaluación retrospectiva del gobierno sí lo hizo. La aprobación del gobierno del PAC saliente favoreció el voto por este partido, mientras que disminuyó la probabilidad de votar por RN $\mathrm{u}$ otros. Se observa aquí el mecanismo de lealtad y castigo funcionando como en elecciones anteriores (Pignataro 2017a). El voto económico, por el contrario, no adquiere validez en el caso costarricense, como han observado otros trabajos (Nadeau et al. 2017).

El voto en la segunda vuelta se modela con las mismas variables explicativas, añadiéndose el voto en el primer turno (PAC vs. demás partidos) (gráfico 6) ${ }^{10}$. A diferencia de la primera votación, la edad no se correlaciona con el voto, como tampoco el sexo. Los niveles educativos superior y secundario reflejan mayor probabilidad de votar por el PAC. La identificación religiosa católica influyó en el voto por este último, mientras que la religión evangélica y la mayor práctica religiosa disminuyeron la probabilidad de voto por este partido. Entre las variables de economía, solo provincia central refleja un efecto (positivo) significativo. Como se esperaba, la aprobación del gobierno Solís favoreció al candidato de su mismo partido. Por último, existe un electorado que votó PAC en ambas ocasiones, mostrando un patrón de fidelidad al partido que implica un aumento de 0,4 puntos porcentuales en la probabilidad del voto de la segunda vuelta.

Los modelos confirman la relevancia de las identidades católica y evangélica y el efecto de la religiosidad. Sin embargo, este factor tampoco debe sobredimensionarse pues, al menos en el momento de realizarse la encuesta, el impacto de la identificación católica en la intención de voto para la segunda vuelta es menor a los efectos del nivel educativo superior, la evaluación retrospectiva del gobierno y el voto por PAC en el primer turno.

Resultan menos relevantes los temas de valencia (excluyendo la valoración retrospectivadelgobierno), laeconomía personalylosfactoressociodemográficos, aunque la edad en la primera vuelta presentó un comportamiento interesante, ya que personas de menor edad votaron PAC y RN con mayor probabilidad. Este hallazgo llama la atención pues desmiente una supuesta homogeneidad de las generaciones jóvenes en términos culturales (i.e., progresistas, posmateriales, etcétera). En cambio, tanto el PAC como RN — partidos, valga decirlo, relativamente jóvenes en su creación - captaron votantes de menor edad que, posiblemente, presentan actitudes sobre autoexpresión y secularidad muy diversas.

10 La variable dependiente corresponde a intención de voto en lugar del recuerdo, ya que se utilizó la base de datos poselectoral de marzo de 2018 con el fin de especificar modelos con variables explicativas idénticas. La encuesta registra una intención de voto por el pac de 54,7 \% (margen de error de $\pm 3,4$ puntos porcentuales), mientras que, en la elección, 60,6 \% votó por este partido. 
Gráfico 6. Efectos marginales en la estimación del voto para la segunda vuelta (modelo logístico)

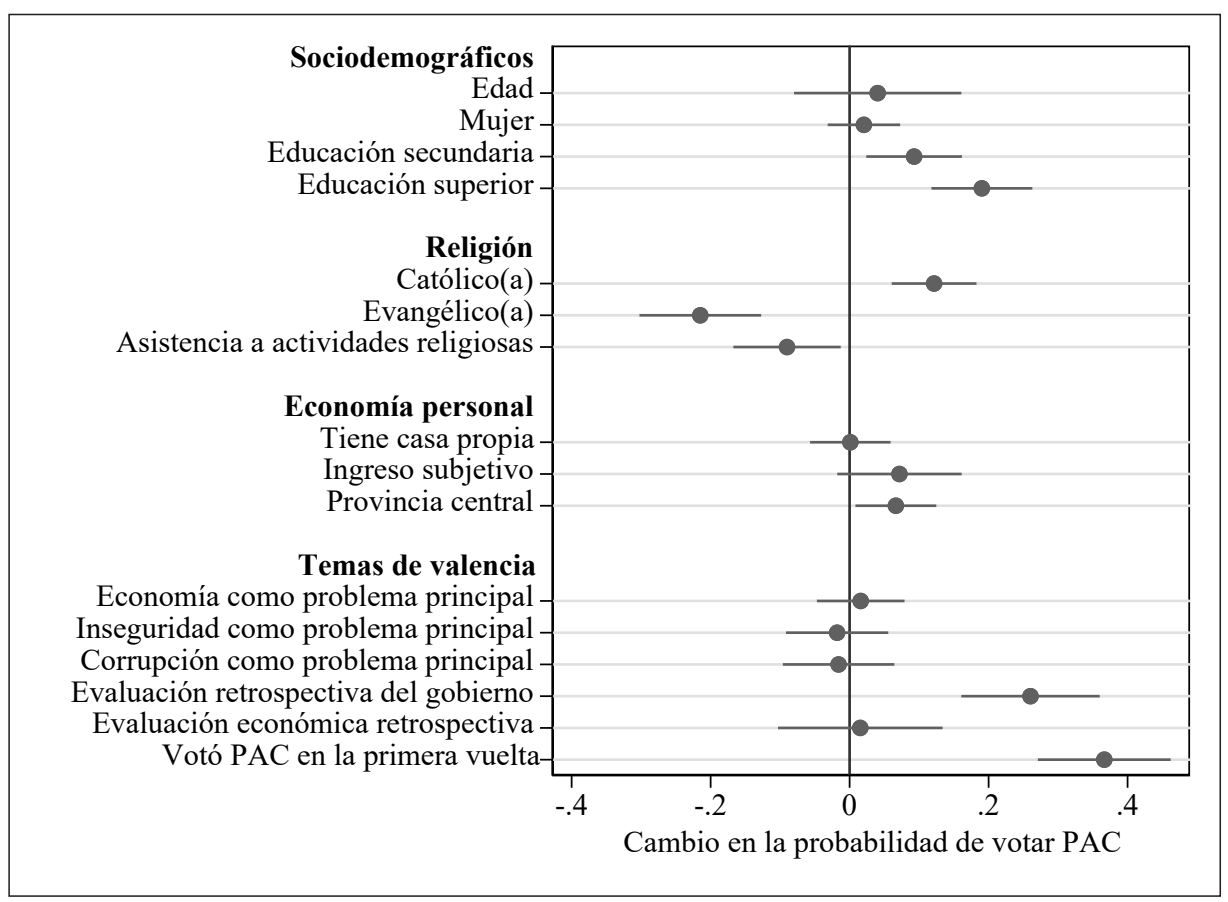

Fuente: Análisis de regresión con base en la encuesta poselectoral de marzo de 2018 del cIEP

\section{VII.CONCLUSIONES}

Las elecciones de 2018 mostraron características distintivas. El candidato oficialista Carlos Alvarado ganó el balotaje pese a la baja popularidad del gobierno saliente, pero no obtuvo mayoría en el parlamento. Partidos con discursos de derecha radical populista surgieron con fuerza. La economía, que inicialmente se planteaba como prioridad para el público, terminó siendo desplazada por temas culturales: aborto, matrimonio igualitario y secularidad. La religión jugó un papel crucial: en la primera vuelta las personas evangélicas votaron predominantemente por el partido neopentecostal Restauración Nacional (RN), mientras que las personas con menor religiosidad en términos de práctica tendieron al voto por el PAC. En el segundo turno, la identidad católica se asoció con el voto por PAC mientras que RN conservó su arraigo entre evangélicos y personas con mayor religiosidad en términos de práctica.

La división religiosa y cultural que estructuró las elecciones de 2018 resulta novedosa no solo para Costa Rica sino en la región latinoamericana, donde la competencia partidaria tradicionalmente se ha configurado en torno a los conflictos económicos-distributivos (Kitschelt et al. 2010). No obstante, debe agregarse dos acotaciones: primero, la relación entre religión y voto es 
probabilística, no determinística; segundo, otras variables influyeron también, en particular edad, nivel educativo, provincia de procedencia y evaluación retrospectiva del gobierno.

Las divergentes preferencias respecto a valores de autoexpresión no nacieron en las elecciones (ver Pignataro y Cascante 2018), sino que adquirieron preponderancia por una interacción de acontecimientos durante la campaña y la movilización estratégica que ciertos actores realizaron (partidarios y no partidarios). En tanto la división cultural responde a procesos de larga duración, su permanencia en la agenda pública y protagonismo en futuras elecciones dependería más bien de la oferta partidaria.

Las nuevas fuerzas políticas identificadas como populismo de derecha, que combinan nacionalismo y autoritarismo, aunque contarán con representación legislativa hasta 2022, muestran dificultades organizativas. Juan Diego Castro se separó del partido en el que construyó su candidatura, atacando a sus líderes y distanciándose de los diputados. El partido de Fabricio Alvarado se fracturó en dos. El grupo leal a Alvarado, que incluye ocho legisladores, impulsa un nuevo partido - Nueva República - para participar de las elecciones municipales que se celebran a medio período (febrero de 2020). Restauración Nacional conserva un grupo de seis diputados, mientras debe responder a denuncias sobre su financiamiento electoral. Sin embargo, debido a la personalización de la política, estas incisiones no impedirían futuras candidaturas presidenciales, teniendo en cuenta que el apoyo electoral para ambos candidatos superó en 2018 el caudal histórico de sus partidos.

Dada la fragmentación partidaria en el parlamento y las fracturas en la opinión pública, el presidente electo conformó un gobierno de coalición con las fuerzas políticas que le dieron su adhesión en la recta final de la campaña, con miras a extender su apoyo en el Poder Legislativo. Para ello distribuyó las carteras ministeriales de primera línea (Escobar-Lemmon y Taylor-Robinson 2005) entre su partido y el PUSc (el excandidato Piza fue nombrado ministro de la Presidencia), mientras que otros miembros del gabinete, de procedencia liberacionista y frenteamplista, recibieron carteras en segunda y tercera línea.

El inicio del gobierno de Carlos Alvarado estuvo marcado por la crisis fiscal no resuelta por los últimos gobiernos, por lo que los esfuerzos de la administración se centraron en la aprobación del cuerpo de proyectos de ley heredados del gobierno saliente para paliar los efectos del déficit. Grupos de opositores liderados por sindicatos se manifestaron en una extensa huelga en contra de la nueva legislación, la cual incluye la introducción del impuesto de valor agregado, reformas al impuesto de renta y restricciones a incentivos salariales en el empleo público. No obstante, la coalición de partidos que conforman el Poder Ejecutivo tuvo réditos en la Asamblea Legislativa pues se consiguió aprobar el llamado "plan fiscal" con miembros de diversas fracciones (34 vs. 17 en la votación final), además porque la emergencia fiscal amenazaba la actividad económica y señalaba al Poder Legislativo como el órgano responsable de la parálisis de la 
reforma fiscal. En su aprobación tuvo un papel destacado la presidencia de la Asamblea Legislativa, en manos del PAC, pues le permitió colocar el proyecto como la prioridad de su primer año de gestión.

A pesar del gabinete multipartidario y de la aprobación del proyecto fiscal, el Ejecutivo no cuenta con una coalición legislativa estable en el Congreso ni con el respaldo de la opinión pública. Un síntoma de ello es la baja aprobación con que inicia su mandato. Aunque el éxito con la reforma fiscal dio un respiro importante al presidente, al ofrecer una imagen de alivio económico y de liderazgo legislativo, los efectos sobre las finanzas públicas empezarán a observarse a mediano plazo. Por otro lado, la agenda cultural continúa más en impasse que en avance. La Sala Constitucional ordenó a la Asamblea Legislativa aprobar el matrimonio igualitario en la normativa correspondiente con un plazo de dieciocho meses, mientras que legisladores conservadores han presentado propuestas de ley en sentido opuesto. Por su parte, el gobierno no ha promovido una agenda progresista, exceptuando el nombramiento de un comisionado presidencial para asuntos LGBTI. Es decir, pese a la polarización cultural (más bien, a causa de ella), el principal logro del gobierno se ubica en el área económica.

De los acontecimientos políticos de 2018 queda pendiente determinar, primero, si la oferta política se radicalizó de forma permanente y, segundo, si la religión y los valores de autoexpresión constituyen un clivaje que estructurarían identidades políticas y el voto, más allá de las contingencias de campaña. Las respuestas serían indicativas sobre cuánto fue la elección de 2018 un caso excepcional y cuánto el inicio de una nueva era política, sobre todo al considerar que en los últimos procesos electorales latinoamericanos los partidos neopentecostales han ganado fuerza política, consolidando su influencia en la arena pública.

\section{REFERENCIAS}

Alfaro, Josué. 2018, 31 de enero. “'Mano dura': el sello de la campaña de Juan Diego Castro". Semanario Universidad. Recuperado el 28 de enero de 2019 de https: / semanariouniversidad.com/pais/mano-dura-sello-la-campana-juan-diego-castro/

Alfaro-Redondo, Ronald. 2006. "Elecciones nacionales 2006 en Costa Rica y la recomposición del sistema de partidos políticos". Revista de Ciencia Política 26 (1): 125-137.

Alfaro-Redondo, Ronald. 2014. "Lifecycle Changes And The Activation Of Habitual Voting: The Case of Costa Rica". Electoral Studies 35: 188-199.

Alfaro-Redondo, Ronald y Steffan Gómez-Campos. 2014. “Costa Rica: elecciones en el contexto político más adverso arrojan la mayor fragmentación partidaria en 60 años". Revista de Ciencia Política 34 (1): 125-144.

Arguedas-Ramírez, Gabriela. 2018. “Gender Ideology, Religious Fundamentalism and the Electoral Campaign (2017-2018) in Costa Rica". Recuperado el 24 de enero de 2019 de http://blogs.lse.ac.uk/gender/category/anti-gender/

Arrieta, Esteban. 2017, 8 de junio. “¿Qué piensa el PIN de migración, impuestos y matrimonio gay?" La República. Recuperado el 28 de enero de 2019 de https:/ / www.larepublica. net/noticia/que-piensa-el-pin-de-migracion-impuestos-y-matrimonio-gay 
Booth, John A. 2007. "Political Parties in Costa Rica: Democratic Stability and Party System Change in a Latin American Context". En Party Politics in New Democracies, editado por Paul Webb y Stephen White. New York: Oxford University Press, 305-344.

Borges, Fabián. 2017. “Costa Rica: la tercera no fue la vencida, fracaso de la reforma fiscal de Luis Guillermo Solís". Revista de Ciencia Política 37 (2): 389-412.

Cascante, Luis Fernando. 2018, 27 de marzo. "Fabricio Alvarado busca combatir criminalidad con mano dura y castigos más severos". La Nación. Recuperado el 28 de enero de 2019 de https://semanariouniversidad.com/pais/fabricio-alvarado-busca-combatir-criminalidad-con-mano-dura-y-castigos-mas-severos/

Carlin, Ryan et al. 2018. "Public Support for Latin American Presidents: The Cyclical Model in Comparative Perspective". Research and Politics 5 (3): 1-8.

Chinchilla, Sofía. 2018, 10 de enero. "Debate organizado por Iglesia: 44 candidatos se comprometen a bloquear matrimonio gay". La Nación. Recuperado el 28 de enero de 2019 de https://www.nacion.com/el-pais/politica/candidatos-debaten-sobre-matrimonio-gay-en-debate/3JQGU5BBDRFW3PTRNKYDYTKV6Q/story/

CIEP. 2017. Informe de resultados de la encuesta de opinión sociopolítica realizada en octubre de 2017. San José: Centro de Investigación y Estudios Políticos, Universidad de Costa Rica.

CIEP. 2018. Informe de resultados de la encuesta de opinión sociopolítica realizada en enero de 2018. San José: Centro de Investigación y Estudios Políticos, Universidad de Costa Rica.

CIEP. 2014-2018. Bases de datos del proyecto Estudios de Opinión Pública. Ciudad: Centro de Investigación y Estudios Políticos, Universidad de Costa Rica.

Corte Interamericana de Derechos Humanos. 2017. “Opinión Consultiva OC-24/7 de 24 de noviembre de 2017 solicitada por la República de Costa Rica". Recuperado el 24 de enero de 2019 de http:/ / www.corteidh.or.cr/docs/opiniones/seriea_24_esp.pdf

Escobar-Lemmon, Maria y Michelle M. Taylor-Robinson. 2005. "Women Ministers in Latin American Government: When, Where, and Why?". American Journal of Political Science 49 (4): 829-844.

Golder, Matt. 2016. "Far Right Parties in Europe". Annual Review of Political Science 19: 477-497.

Green, Jane y Will Jennings. 2017. The Politics of Competence: Parties, Public Opinion and Voters. New York: Cambridge University Press.

Hernández, Óscar. 1991. "Análisis del abstencionismo en las elecciones presidenciales de Costa Rica en el periodo 1953-1986". Anuario de Estudios Centroamericanos 16-17 (2-1): 117137.

Inglehart, Ronald. 2018. Cultural Evolution. People's Motivation are Changing, and Reshaping the World. New York: Cambridge University Press.

Kernecker Theresa y Markus Wagner. 2019. "Niche parties in Latin America". Journal of Elections, Public Opinion and Parties 29 (1): 102-124.

Kitschelt, Herbert et al. 2010. Latin American Party Systems. New York: Cambridge University Press.

Kourliandsky, Jean-Jacques. 2019. “Democracia, evangelismo y reacción conservadora”. Nueva Sociedad 280: 139-146.

Mudde, Cas. 2010. "The Populist Radical Right: A Pathological Normalcy". West European Politics 33 (6): 1167-1186.

Murillo, Álvaro. 2017, 6 de diciembre. "Juan Diego Castro, el temor y la furia". Semanario Universidad. Recuperado el 28 de enero de 2019 de https://semanariouniversidad. $\mathrm{com} /$ pais/juan-diego-castro-temor-la-furia /

Nadeau, Richard et al. 2017. Latin American Elections: Choice and Change. Ann Arbor: University of Michigan Press.

Oro, Ari Pedro y Marcelo Tadvald. 2019. "Consideraciones sobre el campo evangélico brasileño". Nueva Sociedad 280: 55-67.

Partido Integración Nacional. 2017. El País Azul. Perspectivas para la Reconstrucción Nacional. San José: Partido Integración Nacional. 
Pew Research Center. 2014, 13 de noviembre. "Religion in Latin America. Widespread Change in a Historically Catholic Region". Recuperado el 10 de julio de 2019 de https: / / www. pewforum.org/2014/11/13/religion-in-latin-america/

Pignataro, Adrián. 2017a. "Lealtad y castigo: comportamiento electoral en Costa Rica". Revista Uruguaya de Ciencia Política 26 (2): 7-25.

Pignataro, Adrián. 2017b. "Momento de decisión del voto en la era del desalineamiento: el caso de Costa Rica en 2014". Política y Gobierno 24 (2): 409-434.

Pignataro, Adrián y María José Cascante. 2018. Los electorados de la democracia costarricense. Percepciones ciudadanas y participación en torno a las elecciones nacionales de 2014. San José: Editorial IFED.

Programa Estado de la Nación. 2017. Base de datos compendio social. San José: PEN.

Programa Estado de la Nación. 2018. Informe Estado de la Nación 2018. San José: PEN.

Ramírez, Olman (editor). 2010. Comportamiento del electorado costarricense. Elecciones del 2006. San José: Editorial UCR.

Raventós, Ciska et al. 2005. Abstencionistas en Costa Rica. ¿Quiénes son y por qué no votan? San José: Editorial UCR, IIDH-CAPEL, TSE.

Raventós, Ciska et al. 2012. Respuestas ciudadanas ante el malestar con la política: salida, voz y lealtad. San José: IFED.

Remmer, Karen L. 2010. "Political Scale and Electoral Turnout: Evidence From the Less Industrialized World". Comparative Political Studies 43 (3): 275-303.

Restauración Nacional. 2017. Plan de Gobierno 2018-2022. San José: Partido Restauración Nacional.

Restauración Nacional. 2018. Hagámoslo juntos. Por un gobierno de unidad nacional. Plan de Gobierno 2.0. San José: Partido Restauración Nacional.

Ruiz, Gerardo. 2018, 18 de marzo. "Rony Chaves: Apóstol y sombra de Fabricio Alvarado". La Nación. Recuperado el 12 de febrero de 2019 de https: / / www.nacion.com/el-pais / politica/rony-chaves-apostol-y-sombra-de-fabricio-alvarado/3VCFXSJIWZD47DYRXM5I2DZU6A/story/

Sánchez, Fernando. 2003. "Cambio en la dinámica electoral en Costa Rica: un caso de desalineamiento". América Latina Hoy 35: 115-146.

Sequeira, Aarón. 2017, 30 de mayo. "Juan Diego Castro lanza su aspiración presidencial por el PIN con ataque a los 'partidos tradicionales'”. La Nación. Recuperado el 28 de enero de 2019 de https:/ / www.nacion.com/el-pais/politica/juan-diego-castro-lanza-su-aspiracion-presidencial-por-el-pin-con-ataque-a-los-partidos-tradicionales/FIDUCFBTP5HHBCYWBWAO2CFGTE/story/

Stokes, Donald E. 1963. "Spatial Models of Party Competition". The American Political Science Review 57 (2): 368-377.

Treminio, Ilka. 2016. "El PAC al poder. Elecciones 2014 y los principales cambios en el sistema político costarricense". Península 11 (1): 103-126.

Tribunal Supremo de Elecciones. 2018. Estadísticas del sufragio febrero 2018: Presidencia, Vicepresidencias y Diputaciones, primera vuelta. San José: Tribunal Supremo de Elecciones.

Valverde, Rita. 2018, 23 de enero. "Fabricio Alvarado: Costa Rica quiere que defiendan su valores y principios fundamentales". Semanario Universidad. Recuperado el 28 de enero de 2019 de https://semanariouniversidad.com/ultima-hora/fabricio-alvarado-costa-rica-quiere-defiendan-valores-principios-fundamentales/

Vargas-Cullell, Jorge. 2007. "Costa Rica: fin de una era política". Revista de Ciencia Política volumen especial: 113-128.

Zamora, Eugenia. 2018. Mujeres y derechos políticos electorales. Costa Rica: 1988-2018. San José: IFED-TSE.

Recibido: 20 de febrero de 2019

Aceptado: 13 de julio de 2019 
Ilka Treminio: Doctora en Procesos Políticos Contemporáneos, Universidad de Salamanca, España. Profesora de la Escuela de Ciencias Políticas de la Universidad de Costa Rica y directora de la Sede Académica de FLACSO Costa Rica. Correo electrónico: ilka@flacso.or.cr

Adrián Pignataro: Candidato a doctor en Ciencia Política, Scuola Superiore Sant'Anna y Università di Siena, Italia. Docente de la Escuela de Ciencias Políticas de la Universidad de Costa Rica. Correo electrónico: adrian.pignataro@gmail.com 